Obere Extremität 2012 · 7:187

DOI 10.1007/s11678-012-0197-6

Online publiziert: 7. Dezember 2012

c) Springer-Verlag Berlin Heidelberg 2012

\section{Online-Einreichung von Manuskripten für die „Obere Extremität"}

gespeichert, der regelmäßig gesichert wird, sodass ein Datenverlust nicht vorkommt.

- Spart Ihnen Kosten: Es ist kein teurer Postversand mehr nötig. Die Einreichung ist in kürzester Zeit nach ihrer Einspeisung und Bestätigung beim Herausgeber.

Weitere Informationen zum Verfassen und Einreichen von Manuskripten finden Sie in der nebenstehenden Infobox.

Ihre

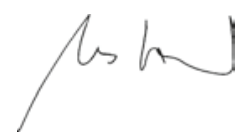

Prof. Dr. M. Loew

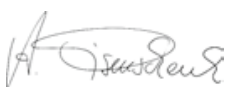

Prof. Dr. A. Eisenschenk

\section{Schriftleitung}

Prof. Dr. med. Markus Loew

Zentrum für Schulter- und

Ellenbogenchirurgie

ATOS Klinik Heidelberg

Bismarckstraße 9-15

69115 Heidelberg

loew@atos.de

Prof. Dr. med. Andreas Eisenschenk Abteilung Hand-, Replantationsund Mikrochirurgie Unfallkrankenhaus Berlin

Warener Straße 7, 12683 Berlin andreas.eisenschenk@ukb.de

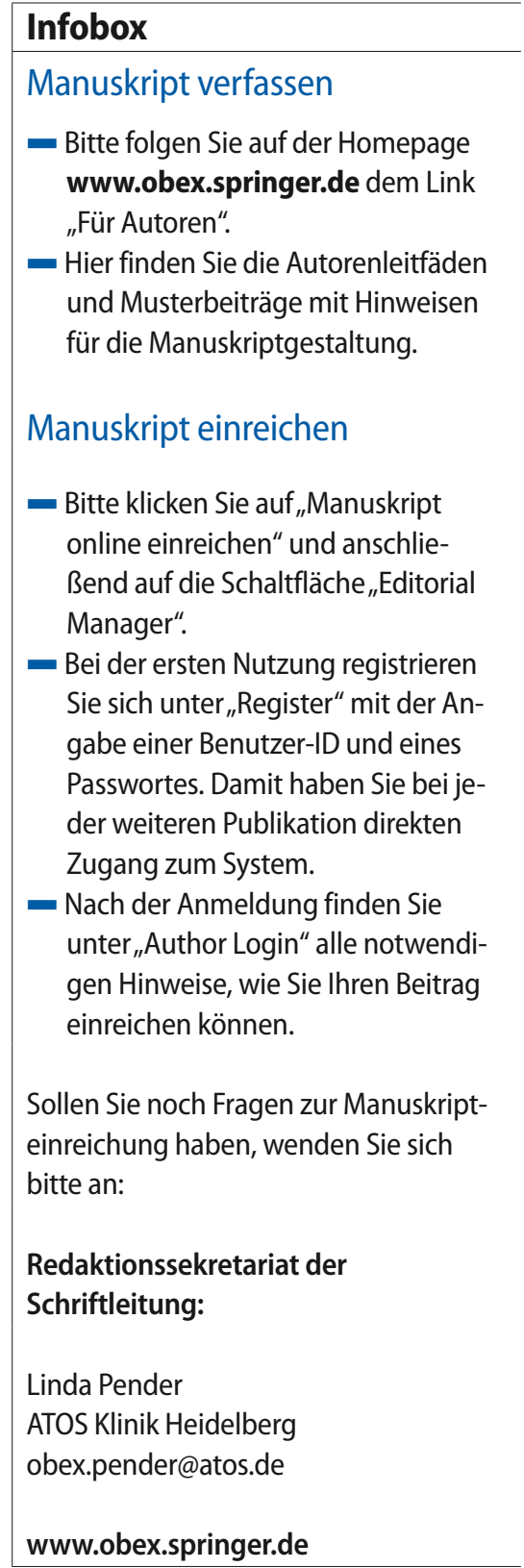

- Ihre Daten sind sicher: Sie werden auf dem sicheren zentralen Datenserver 